\title{
Epidemiology of ectopic pregnancy at Laquintinie Douala hospital (Cameroon): prevalence survey, clinical profile, therapeutic and transfusion issues
}

\section{Henri Essome ${ }^{1,2 *}$, Théophile N. Nana ${ }^{3}$, Grégory E. Halle ${ }^{3}$, Thomas O. Egbe ${ }^{3}$, Merlin Boten², Grâce T. Tocki ${ }^{2}$, Pascal Foumane ${ }^{4}$}

\author{
${ }^{1}$ Faculty of Medicine and Pharmaceutical Sciences of Douala (University of Douala), Laquintinie Hospital in Douala, \\ Cameroon \\ ${ }^{2}$ Laquintinie Hospital in Douala, Cameroon \\ ${ }^{3}$ Faculty of health sciences (University of Buea), Cameroon \\ ${ }^{4}$ Yaoundé Faculty of Medicine and Biomedical Sciences (University of Yaoundé 1)
}

Received: 01 October 2020

Accepted: 09 December 2020

\section{*Correspondence: \\ Dr. Henri Essome, \\ E-mail: essometocky@yahoo.com}

Copyright: (c) the author(s), publisher and licensee Medip Academy. This is an open-access article distributed under the terms of the Creative Commons Attribution Non-Commercial License, which permits unrestricted non-commercial use, distribution, and reproduction in any medium, provided the original work is properly cited.

\begin{abstract}
Background: Pregnancy is a serious pathology of the first trimester of pregnancy and is the leading cause of death. The objective of our work was to determine the hospital prevalence of ectopic pregnancy (EP), to describe the epidemiological, clinical and therapeutic profile given the often-haemorrhagic context at Laquintinie Hospital in Douala.

Methods: We carried out a retrospective study over 10 years, from January $1^{\text {st }}, 2007$ to December $31^{\text {st }}$, 2016, using the operating theatre registers and the files of patients admitted during this period for ectopic pregnancy in the gynaecology and obstetrics department of the Laquintinie Hospital in Douala.

Results: A total of 905 cases of EP for 32,595 deliveries were recorded, for an overall incidence of $2.8 \%$. EP mainly affected the age group of 25 to $35(60.6 \%)$, single people $(57.9 \%)$ and housewives $(46.6 \%)$. The risk factors found were similar to those of cervical cancer, namely multiple sexual partners $(80.4 \%)$, the precocity of sexual intercourse under 18 years $(54.1 \%)$ and sexually transmitted infections $(52.5 \%)$. The symptomatic triad (pelvic pain, amenorrhea and metrorrhagia) was found in $46.1 \%$ of cases with a respective order of frequency of $96.9 \%, 77.3 \%$ and $63.6 \%$ The management was essentially surgical by radical laparotomy (97\% of cases). Two of the 07 deaths were due to religious considerations.
\end{abstract}

Conclusions: EP remains a frequent pathology in our environment with a heavy toll of tubal amputations and death.

Keywords: Death, Ectopic pregnancy, Laparotomy, Transfusion

\section{INTRODUCTION}

Ectopic pregnancies (EPs) are defined as the implantation of the product of conception outside the uterine cavity. They can be life threatening, through a tubal rupture leading to haemo-peritoneum, or even death from hemorrhagic shock. As such, EPs constitute a real diagnostic and therapeutic emergency. ${ }^{1}$ Being able to go from simple pelvic pain to a state of shock with hemodynamic disturbance or even death by hemorrhage after tubal rupture, EP represents until proof of the contrary the diagnosis to be eliminated in priority in a woman of childbearing age with pelvic pain and / or metrorrhagia. ${ }^{1}$ The incidence of EP is distributed across the planet, varying between $1-2 \%$ of pregnancies. In France, this incidence has doubled or even tripled in the 
last two decades with low mortality: one reported annual case. $^{2}$ In 1970 , the incidence of ectopic pregnancy was 4.5 per 1,000 deliveries in the United States. ${ }^{3}$ This incidence increased considerably, going from 4.5 to 19.7 per 1000 deliveries in $1992 .^{3}$

In the developing world, the incidence of EP is higher, reaching $4 \%$ in some regions. ${ }^{4} \mathrm{~A}$ study carried out at the teaching hospital of obstetrics and gynecology of Befelatanana (Madagascar), found an incidence of $2.48 \%$ in 2011; that made in Libreville (Gabon) found an incidence of $2.32 \%$ in $2002.5,6$

In Cameroon, Leke et al reported an incidence of $0.79 \%$ at the Central Hospital of Yaoundé; against 2.3\% found by Dohbit et al at the Bafoussam Regional Hospital in 2010 and $3.45 \%$ found by Kenfack et al in Sangmelima in $2012 .^{7-9}$

The increased incidence of ectopic pregnancy may be associated with an increased prevalence of risk factors. Therefore, knowledge of these risk factors is essential in the case of EP. ${ }^{10}$ It has three interests: to allow primary prevention of EP by eliminating risk factors, to allow secondary prevention by detecting EP in time in populations at risk and finally, to try to avoid a recurrence.

The work of Coste and Job-Spira demonstrated that almost half of the EPs were linked to a genital infection, more than half of which were linked to Chlamydia trachomatis infections. ${ }^{11}$ A Swedish study by Egger demonstrated the effectiveness of national measures for the early treatment of Chlamydia infections. ${ }^{12}$

These genital Chlamydia infections are decisive risk factors, with a frequency of $5-15 \%$ in France 3, 69\% in Libreville (Gabon). They constitute the most frequent risk factor in Cameroon: in $95 \%$ of cases. ${ }^{2}$ The fight against risk factors has been an active role for the medical community for many years. Ectopic pregnancy is the most frequent gynecological surgical emergency in most developing countries, the most frequent clinical form encountered is rupture accompanied by hemorrhage and thus engaging the vital prognosis. ${ }^{2}$

Once the diagnosis of ectopic pregnancy has been made, the management is diversified ranging from therapeutic abstention to surgical treatment (by laparoscopy or laparotomy) through medical treatment. ${ }^{13}$ Therapeutic abstention, medical treatment and laparoscopy are more and more practiced in our country, surgical management by laparotomy remains the most frequently used therapeutic modality. ${ }^{14}$

As part of our contribution to knowledge on this, we set out to research the epidemiological, clinical and therapeutic profile of ectopic pregnancies at Laquintinie Hospital in Douala.

\section{METHODS}

\section{Type of study, duration and period}

We conducted a retrospective study over 10 years, from January $1^{\text {st }}, 2007$ to December $31^{\text {st }}, 2016$ in the gynaecoobstetrics department of the Laquintinie Hospital in Douala by consulting the theatre registers and archived files of patients admitted for ectopic pregnancy (ruptured or not) during this period.

\section{Study population}

The target population consisted of patients from the Laquintinie Hospital in Douala who had an ectopic pregnancy between January 1st, 2007 and December 31 st, 2016.

\section{Inclusion and exclusion criteria}

Included were all patients who had an ectopic pregnancy at Laquintinie Hospital in Douala between January 1st, 2007 and December 31st, 2016 with usable records. Those whose records were unusable were excluded.

\section{Data sampling and analysis}

Sampling was random. The variables of interest were: age, profession, marital status, parity, gestational age, gynecological and obstetric history, clinical, therapeutic, transfusion and evolutionary aspects. The data were collected using a pre-tested file, entered with Microsoft Word 2010 software and analyzed by SSPP software. The $\mathrm{P}$ values were interpreted at the statistical threshold of $5 \%$ and the confidence intervals at $95 \%$.

\section{Ethical consideration}

The research authorization of the director of the Laquintinie hospital in Douala was obtained; confidentiality and medical confidentiality were respected.

\section{RESULTS}

During the study period, we identified 933 files of patients diagnosed for ectopic pregnancy, 28 of which were unusable and excluded from this fact. The final size of our sample was 905 cases of GEU for 32595 deliveries, achieving a hospital incidence of $2.8 \%$, or a GEU for 36 deliveries (Figure 1).

\section{Socio demographic characteristics}

The mean and the median age of the population were 28.59 and 28 years, respectively, with a standard deviation of 5.32 and extremes of 15 and 45 . They were mostly 25-35 years (60.6\%), single (57.9\%) and housewives $(46.6 \%)$ (Table 1$)$. 


\section{Clinical features}

Multi-sexual partnership $(\geq 2)$ was the dominant risk factor with a frequency of 728 cases, which represented $80.4 \%$ of our sample followed by the earliness of sexual intercourse before 18 years: 490 cases $(54.1 \%)$ ) and sexually transmitted infections: 475 (52.5\%. In $22.7 \%$ of cases $(205)$ the patients were nulli-gravid and nulliparous in $60.8 \%$ of cases $(550)$ (Table 1$)$.

More than half of our sample (57.7\%) (522 cases) consisted of referrals (Figure 2); pelvic pain was the main reason for consultation (45.5\%) (419 cases) (Figure 3) while the triad of pelvic pain, amenorrhea and metrorrhagia was found in $46.1 \%$ on clinical examination in order of frequency $96.9 \%, 77.3 \%$ and $63.6 \%$ respectively (Figure 4). Paracentesis was the most widely used diagnostic means in $93 \%$ of cases (842) with a positivity rate of $86 \%$ (724 cases) (Table 2 ).

Table 1: Distribution by age group, marital status, occupation, gynecological and obstetrical history.

\begin{tabular}{|c|c|c|}
\hline Variables & $\begin{array}{l}\text { Frequency } \\
(\mathrm{n}=905)\end{array}$ & $\begin{array}{l}\text { Percentage } \\
(\%)\end{array}$ \\
\hline \multicolumn{3}{|l|}{ Age (years) } \\
\hline $15-25$ & 222 & 24.5 \\
\hline $25-35$ & 548 & 60.6 \\
\hline $35-45$ & 135 & 14.9 \\
\hline \multicolumn{3}{|l|}{ Marital status } \\
\hline Single & 524 & 57.9 \\
\hline Married & 371 & 41 \\
\hline Divorced & 2 & 0.2 \\
\hline Widow/widower & 8 & 0.8 \\
\hline \multicolumn{3}{|l|}{ Occupation } \\
\hline Housewife & 422 & 46.6 \\
\hline Public sector & 40 & 4.4 \\
\hline Private sector & 69 & 7.6 \\
\hline Student & 143 & 15.8 \\
\hline Informal sector & 231 & 25.5 \\
\hline $\begin{array}{l}\text { Age at first coitus } \leq 18 \\
\text { years }\end{array}$ & 490 & 54.1 \\
\hline Number of partners $\geq \mathbf{2}$ & 728 & 80.4 \\
\hline $\begin{array}{l}\text { History of } \\
\text { STI/Chlamydia }\end{array}$ & 475 & 52.5 \\
\hline History of IUD & 13 & 1.4 \\
\hline History of EP & 50 & 5.5 \\
\hline History of abortion & 211 & 23.3 \\
\hline History of tubal surgery & 10 & 1.1 \\
\hline $\begin{array}{l}\text { History of use of } \\
\text { ovulation stimulants }\end{array}$ & 3 & 0.3 \\
\hline \multicolumn{3}{|l|}{ Gestation } \\
\hline G0 & 205 & 22.7 \\
\hline G1-2 & 700 & 77.3 \\
\hline \multicolumn{3}{|l|}{ Parity } \\
\hline P0 & 550 & 60.8 \\
\hline $\mathrm{P} 1+$ & 355 & 39.2 \\
\hline
\end{tabular}

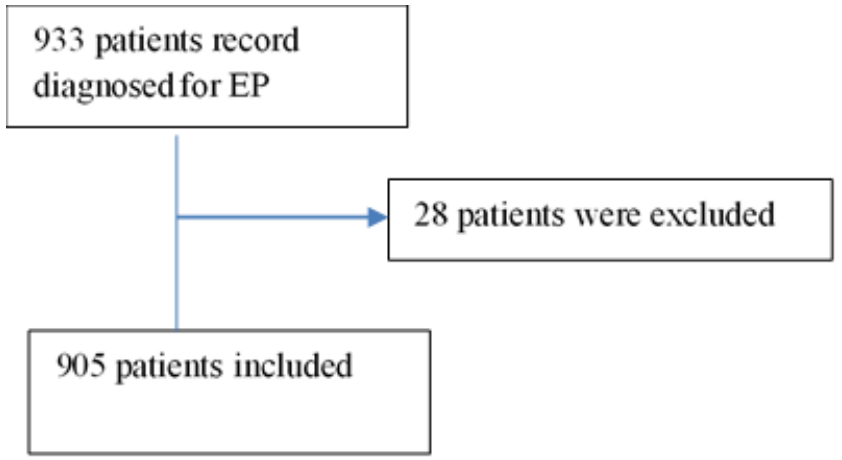

Figure 1: Recruitment diagram.

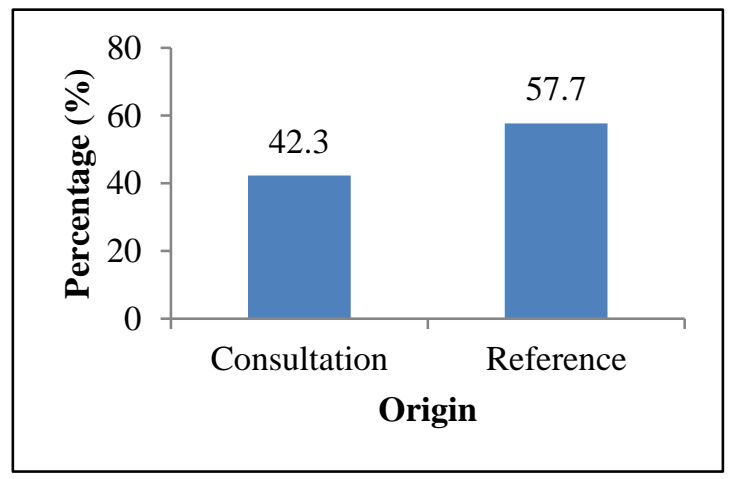

Figure 2: Distribution of patients by origin.

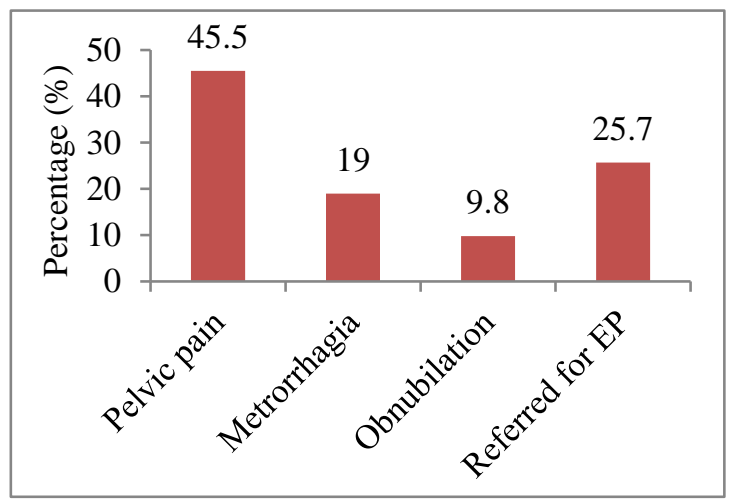

Figure 3: Distribution by reason of admission.

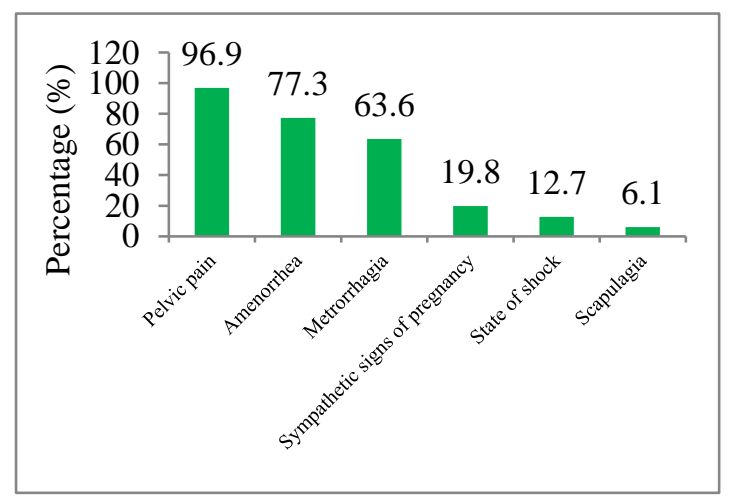

Figure 4: Distribution of the population according to clinical signs and symptoms 
Table 2: Distribution of the population according to the diagnostic examinations used and the results obtained.

\begin{tabular}{|llll|}
\hline Exam realised & Frequency $(\mathbf{n = 9 0 5})$ & Percentages (\%) & Results \\
\hline Paracentesis & 842 & 93.0 & Positive: $724(86,0 \%)$ Negative: $118(14,0 \%)$ \\
\hline Culdocentesis & 130 & 14.4 & Positive: $70(53,8 \%)$ Negative: $60(46,2 \%)$ \\
\hline b-HCG dosage & 178 & 19.7 & Positive: $164(92,1 \%)$ Negative: $14(7,9 \%)$ \\
\hline Ultrasound & 325 & 35.9 & Ruptured EP: $238(73,2 \%)$ Unrupture EP: $87(26,8 \%)$ \\
\hline
\end{tabular}

Table 3: Distribution of the population according to the treatment received.

\begin{tabular}{|llll|}
\hline Type of treatment received & $\begin{array}{l}\text { Frequency } \\
(\mathbf{n = 9 0 5})\end{array}$ & $\begin{array}{l}\text { Percentage } \\
(\%)\end{array}$ \\
\hline Medical treatment & 0 & 0 \\
\hline Therapeutic abstention & 0 & 0 \\
\hline $\begin{array}{l}\text { Surgical } \\
\text { treatment }\end{array}$ & Laparotomy & 905 & 100 \\
\cline { 2 - 4 } & Coelioscopy & $\mathrm{O}$ & 0 \\
\hline
\end{tabular}

Table 4: Distribution of surgical treatment by laparotomy according to the therapeutic alternative

\begin{tabular}{|lll|}
$\begin{array}{l}\text { Therapeutic } \\
\text { alternative }\end{array}$ & $\begin{array}{l}\text { Frequency } \\
(\mathbf{n = 9 0 5 )}\end{array}$ & $\begin{array}{l}\text { Percentage } \\
(\%)\end{array}$ \\
\hline Conservative surgery & 27 & 3 \\
\hline Radical surgery & 878 & 97 \\
\hline
\end{tabular}

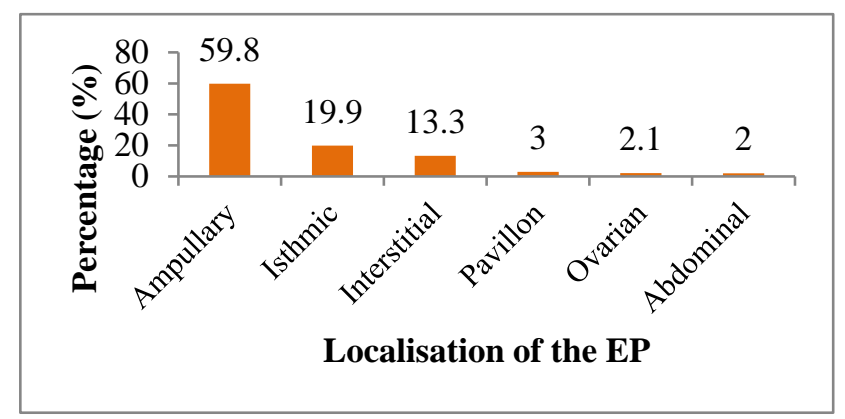

Figure 5: Distribution according to the location of the EP.

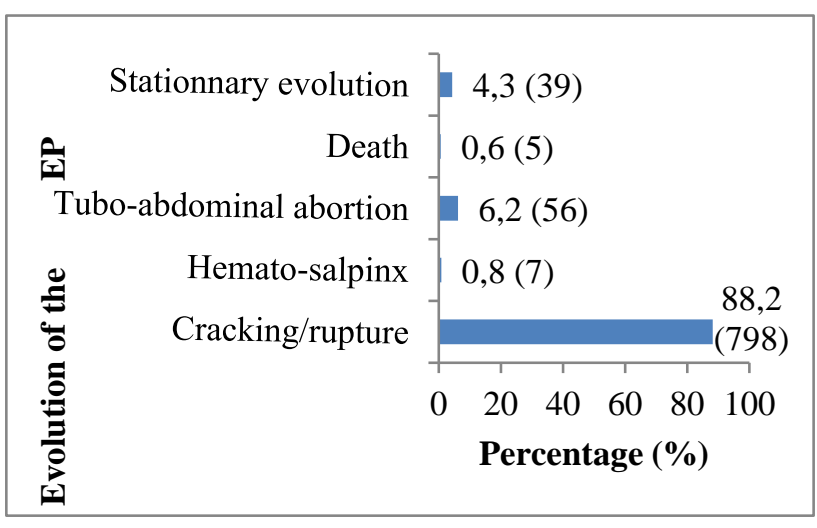

Figure 6: Distribution of the population according to evolution of the EP.
On the other hand, 07 deaths $(0.77 \%)$ were recorded by hemorrhagic shock during this period, including two transfusion refusals due to religious considerations. The treatment was exclusively surgical with a laparotomic approach and mainly radical by salpingectomy in the order of $97 \%$ (878) (Table 3).

Table 5: Distribution according to the reasons for abstention from transfusion.

\begin{tabular}{|c|c|c|}
\hline $\begin{array}{l}\text { Reason for lack of } \\
\text { transfusion }\end{array}$ & $\begin{array}{l}\text { Number } \\
(\mathbf{n}=289)\end{array}$ & $\begin{array}{l}\text { Percentage } \\
(\%)\end{array}$ \\
\hline No need for transfusion & 197 & 68.2 \\
\hline Religious considerations & 62 & 21.5 \\
\hline Blood not available & 27 & 9.4 \\
\hline Lack of equipment & 1 & 0.3 \\
\hline
\end{tabular}

\section{DISCUSSION}

\section{Epidemiological profile}

Socio-demographic characteristics and risk factors

The average age of our population was $28.59 \pm 5.32$ years with extremes of 15 and 45 years. Our results can be superimposed on those of Randriambololona (an average of 30.72 years with extremes of ages 18 and 48) 5 as well as those of Dohbit (average age of 29.69 years with extremes of 18 and 44) 8; the 25-35 years old (constituted the majority $(60.6 \%)$. This is challenging in more ways than one because this age group constitutes the top level of human reproduction and its high percentage will have to elicit advice for behavior change, particularly sexual behavior.

Because the majority risk factor found in our study was the multiplicity of sexual partners $(80.4 \%)$ followed by the precociousness of sexual intercourse before the age of 18 years $(54.1 \%)$ and a history of sexually transmitted infection $(51.4 \%)$.

If the medical literature and previous work on the subject report more history of sexually transmitted infection, our results are not contradictory, however, since the multiplicity of sexual partners is a potential determinant of sexual contamination helped in this by cervical immaturity. Such as the precocity of sexual intercourse in the under-18 age group thereby anticipating the variable 
age greater than 35 years retained in the literature as a risk factor. ${ }^{1}$

This means that the history of induced abortions reported by Randriambololona et al (36\%) 5 as well as the history of PID from the work of Dohbit et al (24.75\%) 8 are only corollaries of a dilapidated sex life such as the mask of our profile presents itself.

If ectopic pregnancy is the tubal sanction of a late egg as a result of a physiologically defective tube, these observations arise as a result of the factors mentioned above by our findings and those of other authors. They often stem from a precarious social experience.On the social level, many of our patients were single $(57.98 \%)$ and housewives $(46.6 \%)$ or working in the informal sector $25.5 \%$. This means that our sample was predominantly low income and therefore at low economic level; therefore exposed to sexual practices that provide infections in accordance with the work of Namaya et al and Thonneau. ${ }^{15-16}$

\section{Clinical profile and diagnostic examinations}

In the majority of studies, GEU is associated with low parity. ${ }^{6,20,21}$ In our series, the average parity was 1.28. The nulliparous and primiparous were the most affected: $60.8 \%$. These results are similar to those of Lankouande et al in Ouagadougou in 1998, as well as those of Sindayirwanya et al in Burundi in 1991.22-17

The symptomatic triad (amenorrhea, pelvialgia and metrorrhagia) was found in $46.1 \%$ of the cases in order of frequency $96.9 \%$ for pelvic pain, $77.3 \%$ for amenorrhea $(77.3 \%)$, and $63,6 \%$ for metrorrhagia unlike the findings of Majhi in whom pelvic pain was predominant $(86.1 \%)$ followed by amenorrhea $(76.1 \%)$ and metrorrhagia $(42.2 \%)$ with, however, a effectiveness of the symptomatic triad confirming data from the literature. ${ }^{1,18}$

In a medical environment with a low technical and financial resource, the clinical approach is often preponderant in our health structures in order to compensate as much for these shortcomings as for the late delays in consultation legions in our communities; this is what justifies as much as other authors in the same geographical area including Dobbit and Kouam our 59\% of cases by clinical diagnosis and paracentesis (93\%) as much as Majhi Nos, $7 \%$ of shock on admission attests to the delay in consultation and sometimes to inaccessibility to care given the precariousness of our popular strata here mainly single and housewives ${ }^{8,18,19}$

Hence the strategy to promote primary prevention by controlling risk factors and secondary prevention by early and effective treatment of genital infections. ${ }^{11,12}$ The findings of other authors are heterogeneous and relate mainly to the health organization and the sizes of the samples. ${ }^{8,17}$ The mean gestational age at the time of admission was $8.76 \pm 2.41$ weeks of amenorrhea similar to the 8SA of Meye et al. ${ }^{6}$

\section{Therapeutic aspects and transfusion issues}

\section{Therapeutic aspects}

As much as other works from the same geographic area and elsewhere, the treatment was surgical and radical by salpingectomy in $97 \%$ of our series. ${ }^{8,19}$ This radical option was justified by the high rate of ruptured GEU in our sample $(88.2 \%)$ with large hemoperitoneum, the average of which was $1556 \pm 916.36 \mathrm{ml}$. Ampullary localization was the most frequent with $59.8 \%$, superimposable on that of Tumenta $(61.9 \%)$, as well as that of Mohamed $(60 \%) .^{20,21}$

\section{Transfusion issues}

The massive hemoperitory with an average of $1556 \pm 916.39 \mathrm{ml}$ explains the use of blood transfusion in the order of $68.1 \%$ of cases (or 616 cases out of 905). But in $21.5 \%$ of the cases the transfusion indication was relevant but not honored because of philosophical and precisely religious barriers, the outcome of which was fatal with the death of 02 patients; this problem requires education of the community masses in order to remove any uncomfortable ambiguity for a practitioner faced with hemodynamic instability of hemorrhagic cause. Because at the severe stage of anemia only hemoglobin replaces hemoglobin, filling with crystalloids is only a waiting measure

\section{Evolving profile and complications of GEU}

\section{Evolutionary profile of the GEU}

The patients arrived at the ruptured stage in $88.2 \%$, or 798 of the cases. These results join the $87.62 \%$ of Dohbit et al. ${ }^{8}$ This high rate is often dependent on the delay in legion consultation in our communities.

\section{Complications of GEU}

Two complications were recorded 11 cases of hemorrhagic shock $(1.2 \%)$ resulting in 07 deaths, two of which by transfusion due to religious considerations $(0.77 \%)$, ie a survival rate of $99.22 \%$ as opposed to Dohbit et al had reported post-operative infection as complications of GEU (1.4\%). ${ }^{8}$

\section{CONCLUSION}

The ectopic pregnancy at Laquintinie hospital has a hospital incidence of $2.8 \%$ with a survival rate of $99.22 \%$ despite religious barriers to blood transfusion which caused 02 deaths out of a total of 07 deaths. The mask of the patient in our study is a single housewife with the same determinants as those of cervical cancer, namely the 
precocity of sexual intercourse, multiple sexual partnership and their corollaries of sexually transmitted infections. All things that call for a strengthening of primary and if necessary secondary prevention strategies.

\section{ACKNOWLEDGMENTS}

Authors would like to thank the management of Laquintinie hospital for the facilities granted to them for the materialization of this study.

Funding: No funding sources

Conflict of interest: None declared

Ethical approval: The study was approved by the Institutional Ethics Committee

\section{REFERENCES}

1. Courbiere B, Carcopino X. KB Gynécologie Obstétrique. 2012;128-139.

2. Madelenat P. Recommendations for clinical practice: management of ectopic pregnancy. J Gynécolobstet Biol Reprod. 2003;32.

3. Centers for disease control and prevention: ectopic pregnancy United States. 1992;273(7):533.

4. Vanitha N, Sivalingam, Duncan C, Kirk E, Lucy AS, Andrew WH. Diagnosis and management of ectopic pregnancy. J Fam Plann Reprod Health Care. 2011;37:231-40.

5. Randriambololona DMA, Anjaharisoaniaina NT, Rekoronirina EB, Harioly MOJ, Randriambelomanana JA, Andrianampanalinarivo RH. Ectopic pregnancy in Madagascar: 107 observations. Med Santé trop. 2012;22(4);394-7.

6. Meyé JF, Sima A, Olé BS, Kendjo E, Beka TE. Aspects actuels de la grossesse extra-utérine à Libreville (Gabon): à propos de 153 cas. Cahiers d'études et de recherches francophones. 2002;12(4):405-8.

7. Leke RJ, Goyaux N, Matsuda T, Thonneau PF. Prenancy in Africa: A population-based study. Obstet Gynecol. 2004;103:692-7.

8. Dohbit JS, Foumane P, Kapche MD, Mboudou ET, Doumbe M, Doh AS. Extrauterine pregnancy at the regional hospital of bafoussam: epidemiological, clinical and therapeutic aspects. Clin Mother Child Health. 2010;7(1).

9. Kenfack B, Noubom M, Bongoe A, Tsaledem FA, Ngono M. Ectopic pregnancy in a semi rural area in South Africa. Pan Afr Med J. 2012;13:71.

12. Iffy L. The role of premenstrual, post mid cycle conception in the étiology of ectopic gestation. J Obstet Gynecol Br Commonw. 1963;70:996-1000.
13. Coste J, Laumon B, Bremond A, Collet P, Job-Spira N. Sexually transmitted diseases as major causes of ectopic pregnancy results from a large case-control study in France. Fertil Steril. 1994;62:289-95.

14. Egger M, Low N, Smith GD, Lind blom B, Herrmann B. Screening for chlamydial infections and the risk of ectopic pregnancy in Sweden: ecological analysis. Br Med J. 1998;316:1776-80.

15. Kulp JL, Kurt TB. Ectopic pregnancy: diagnosis and management. Women's Health. 2008;4(1):79-87.

16. Foumane P, Mboudou ET, Mbakop S, Dohbit J.S, Belinga E, Doh A.S. La place du traitement peu ou non invasif dans la prise en charge de la grossesse extra-utérine à l'hôpital gynéco-obstétrique et pédiatrique de Yaoundé: une analyse rétrospective sur cinq ans. Clin Mother Child Health. 2010;7(1):1201-4.

17. Nayama M, Gallais A, Ousmane N. Management of ectopic pregnancy in developing countries: example of a Nigerian reference maternity. Gynecol Obst Fertil. 2006;34(1):14-8

18. Thonneau P, Hijazi Y, Goyaux N, et al. Ectopic pregnancy in Conakry Guinea. Bull World Health Organ. 2002;80(5):365-70.

19. Sindayirwanya JB, Harakeye MG, Ninteretse G et al. Aspects particuliers des grossesses extra-utérines au Burundi: à propos de 249 cas. Med Afr Noire. 1991;38(5):335-41.

20. Majhi AK, Roy N, Karmakar KS. Ectopic pregnancy-an analysis of 180 cases. J India Med Assoc. 2007; 105(6):308-12.

21. Kouam L, Kamdom-Moyo J. Treatment of ectopic pregnancies by laparotomy in under-equipped countries. A series of 144 cases at the Yaounde University Hospital Center (Cameroon). J Gynecol Obst et Biol Reprod (Paris). 1996;25(8):804-8.

22. Tumenta TS. Clinical and therapeutic aspects of ectopic pregnancy in Yaoundé. (Thèse) (2006): Faculté de Medecine et de Sciences Biomédicales de Yaoundé I.

23. Mohamed R. Prise en charge de la grossesse extrautérine au service de gynéco-obstétrique $\mathrm{B}$, à propos de 86 cas. (Thèse) (2006) Maroc.

Cite this article as: Essome H, Nana TN, Halle GE, Egbe TO, Boten M, Tocki GT, et al. Epidemiology of ectopic pregnancy at Laquintinie Douala hospital (Cameroon): prevalence survey, clinical profile, therapeutic and transfusion issues. Int J Reprod Contracept Obstet Gynecol 2021;10:44-9. 